\title{
Optimized Finned Heat Sinks for Natural Convection Cooling of Outdoor Electronics
}

\author{
Lian-Tuu Yeh, ASME Fellow \\ Thermal Consultant \\ Dallas, TX, USA \\ Email :jjyeh2@aol.com
}

Keywords: Heat sinks, natural convection cooling, outdoor Electronics

Abstract: A series of analysis has been conducted previously to analyze the finned heat sink thermal performance. The analysis is first performed to optimize the fin spacing of a vertical continuous finned heat sink. Both empirical and CFD methods are utilized to obtain the optimal fin spacing of a given heat sink. The results from both methods are in very good agreement. The analysis was then extended to optimize the fin configurations. Three types of fin configurations, namely continuous fins, staggered fins and in-line fins are under consideration. The results from the CFD analysis indicate that the continuous fin configuration is the most effective thermally. Later, the effects of the cover or shrouds at various distances on the heat sink thermal performance are also analyzed. The heat sink with the cover in a direct contact with the fin tips performs best in the heat rejection. For tower or poled mounted electronics, the heat sink weight is extremely important. Therefore, the extrusion fin heat sink is replaced by the plain fin heat sink for weight reduction. This study is aiming at the development of newly developed light weight finned heat sink and its thermal performance under natural convection for cooling of electronics.

\section{Introduction}

Heat transfer by natural (or free) convection has long been considered as one of the most cost effective and reliable cooling methods. Natural convection with air has many practical engineering applications and is of special interest to the cooling of electronic equipment. The advantages of air cooling by natural convection are safe, simple and cost effective.

There are many studies of the natural convection from the multiple surfaces such as parallel plates or finned heat sinks by numerical analysis or by experiment. The finned heat sink as presented in Figure 1 consists of a number of U-shaped channels. The corner regions formed by the base plate and the fins result in a significant reduction in the heat transfer. 


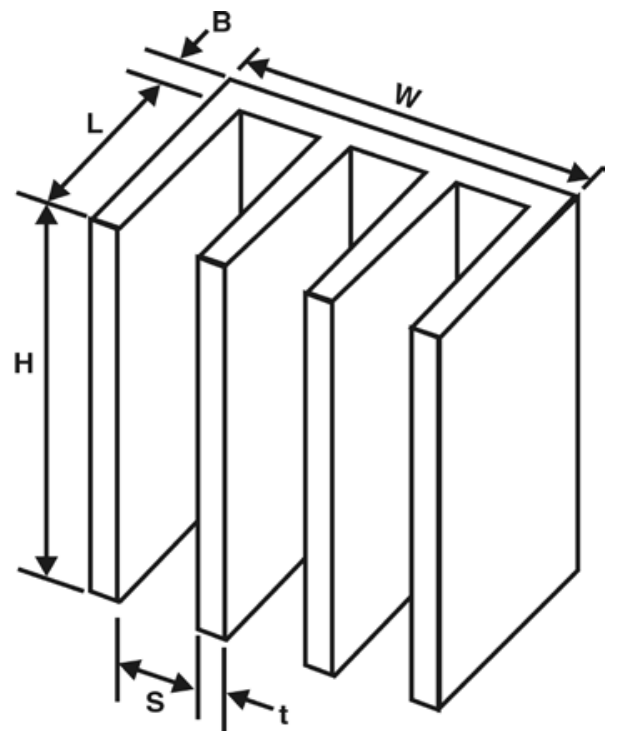

Figure 1 Vertical Straight Fin Heat Sink

For vertically straight- fin heat sinks, several experimental data (1-3) are available. Among them, Izume and Nakamure (3) developed a mathematical relationship describing heat transfer from the finned heat sink, however, their equation does not hold in the limiting cases of very large or very small ratios of the channel depth to channel width. To overcome this problem, Van De Pol and Tierney (4) developed an empirical equation which is applicable to any channel depth to width ratios to compute the U-channel heat transfer coefficient. The correlation is limited to the constant wall temperature condition and is only applicable to the continuous straight fins.

The first step in the analysis is to optimize the fin spacing between the fins for an extrusion heat sink. The process to determine the optimal fin spacing was discussed in details in Reference 5 . A CFD analysis was also included in the same reference. A good agreement in the results was found between the correlations and the CFD analysis. In addition, Yeh et al. (5) performed a CFD analysis on the continuous finned heat sink and also on the staggered and in-line finned heat sinks as shown in Figure 2 at the constant wall temperature conditions. The results indicated that the continuous fins are most efficient thermally.

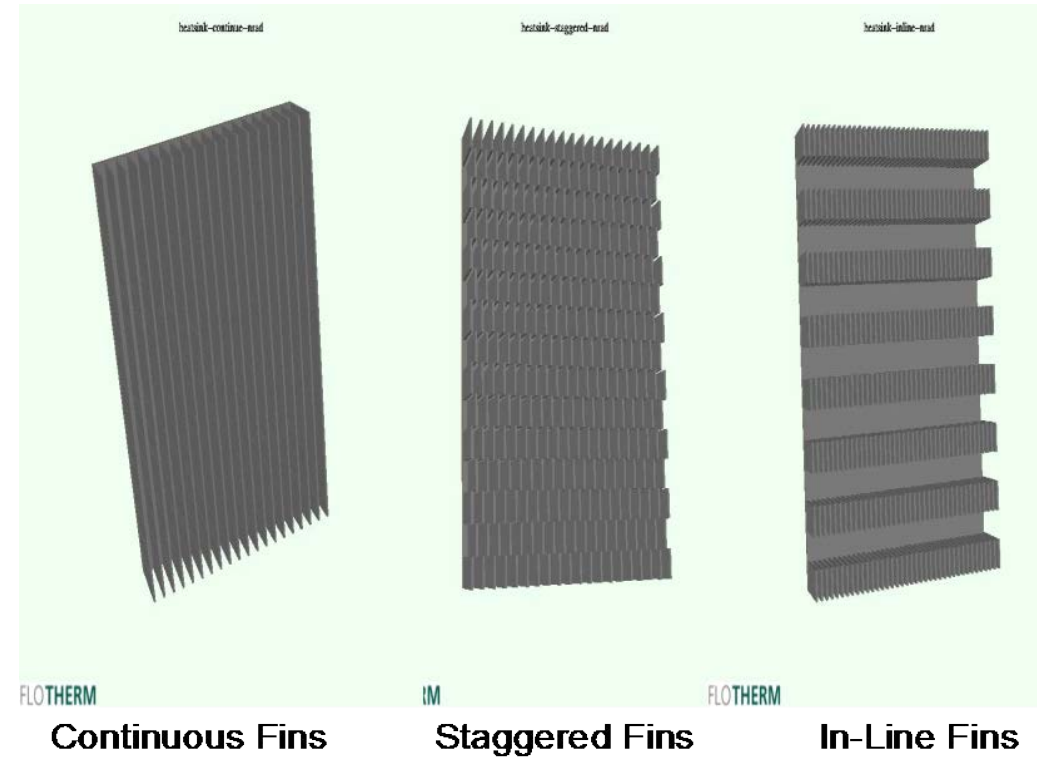

Figure 2 Various Types of Finned Heat Sinks 
Yeh (6) extended the analysis to examine the effects of the cover on the heat transfer. An unheated cover (shroud) is included in the CFD model where the heat sink base is at a constant temperature of 176 ${ }^{\circ} \mathrm{F}$. To further understand the distance effect, the distance between the cover and the fin tip of the heat sink is varied from zero to 99".

The results also indicate that there will be no effect of the cover on the heat loss and entrant flow rate as long as the distance between the cover and the tip of fins is greater than 4.36" with the fin height of 2.0". Based on the limited data in this work, one may conclude that there is no effect of the cover on the heat transfer of a finned heat sink if the distance between the tip of fins and the cover is greater than 2.5 times of the fin height.

The purpose of this work is to employ the knowledge gained from previous studies $(5,6)$ to development of light weight heat sinks for tower or pole mounted electronics.

\section{System descriptions}

The vertical straight fin heat sinks as given in Figure 1 are often employed in cooling of the outdoor electronic equipment because of its simplicity, easy maintenance and reliable. One of its applications is for the tower/pole mounted electronics as shown in Figure 3. The system under consideration includes a RF module with 3 power amplifiers mounted on its housing base plate. The RF module is then mechanically attached to a large heat sink. The cross section of the system and the thermal model are shown in Figure 4. The overall dimensions of the RF modules base plate are $220 \mathrm{~mm}$ x $100 \mathrm{~mm} \times 6 \mathrm{~mm}$. The size of three chips with various chip power (105W, 30W and 5W) is identical and its dimensions are $25 \mathrm{~mm}$ x $15 \mathrm{~mm}$

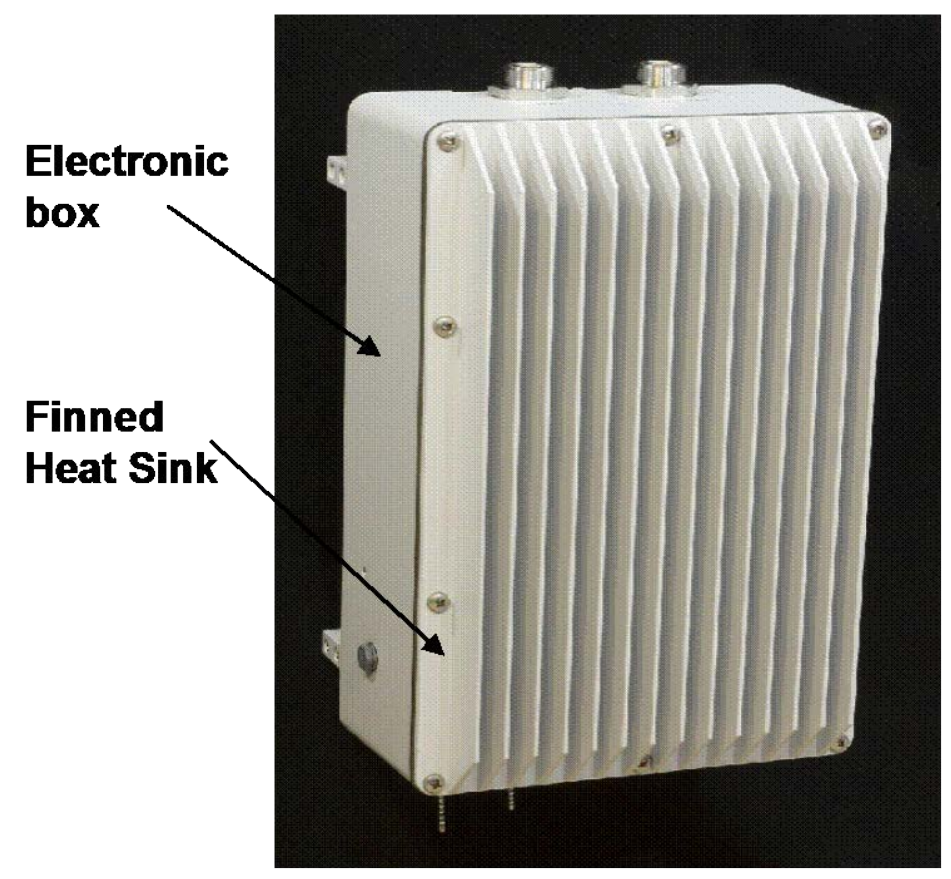

Figure 3 Pole Mounted Electronics with Finned Heat Sink 


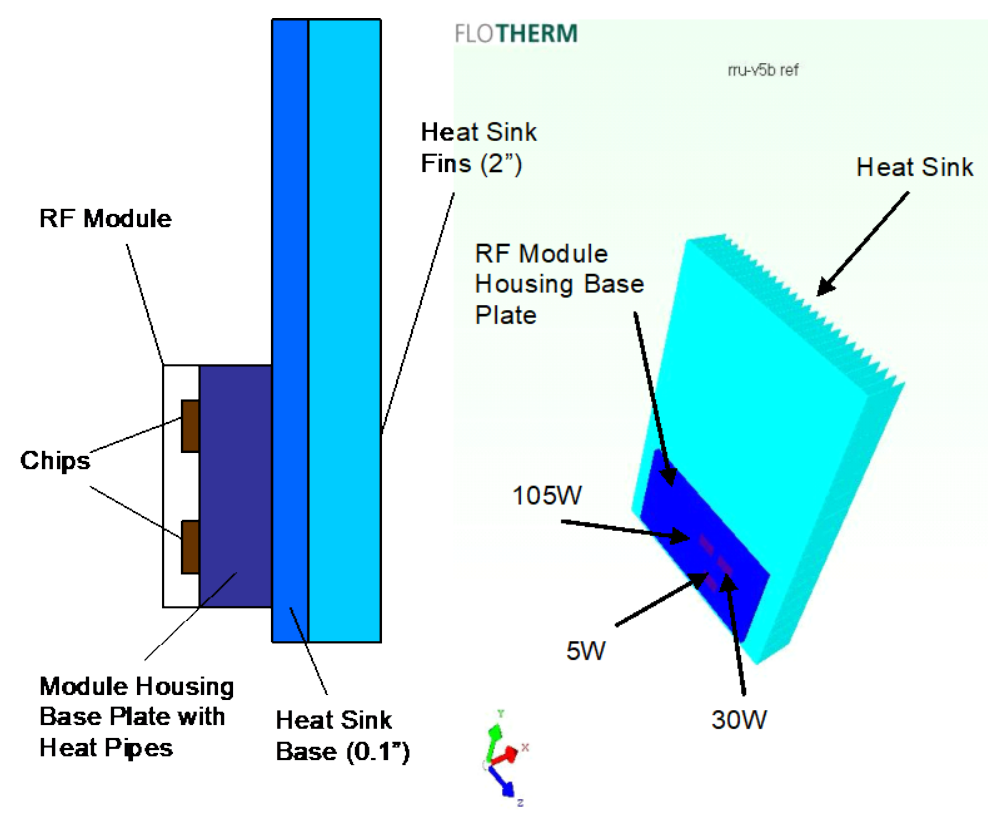

Figure 4 System Cross-Section View and Its thermal Model

\section{Thermal Analysis}

For any tower or pole mounted equipment, the weight of heat sink is very important. The extrusion heat sink described in References 5 and 6 is bulky and heavy because of the thick fins and base. In order to reduce the weight, the plain fin heat sink is employed as illustrated in Figure 5. Following previous studies $(5,6)$, the fin spacing of the heat sink is optimized and the heat sink dimensions are as follows :

Heat sink width $(\mathrm{W})=10.341$ “

Heat sink length $(\mathrm{L})=12$ ”

Heat sink base $(\mathrm{Hb})=0.1$ "

Fin height $(\mathrm{Hf})=2.0$ "

Fin thickness $(\mathrm{t})=0.02$ ”

Number of fins $=22$ (fin spacing of 0.471 ”)

The total heat sink weight is $1.021 \mathrm{Kg}(2.246 \mathrm{Lbm})$. The heat sink is made of AL 6061 with the thermal conductivity of $180 \mathrm{~W} / \mathrm{m}-{ }^{\circ} \mathrm{C}$. It should be noted that all previous studies $(5$, 6) which are idealized and over simplified cases assumed the uniform heat sink base temperature.

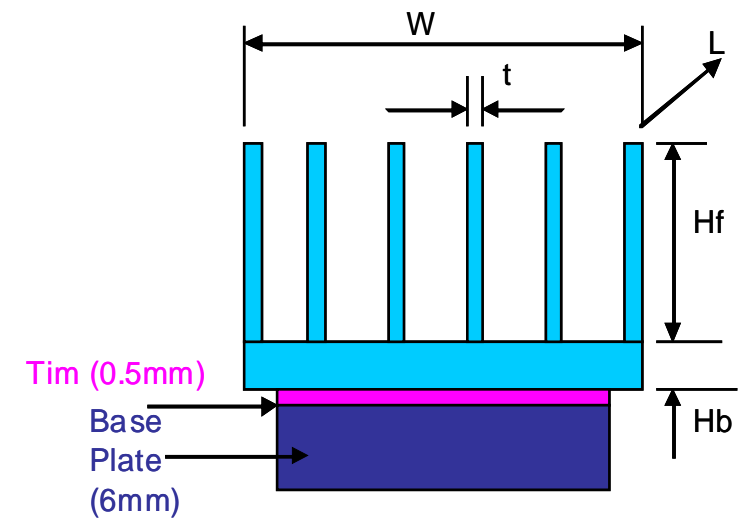

Figure 5 Heat Sink and System under Consideration 
The previous studies $(5,6)$ are limited to the natural convection conditions. Therefore, radiation heat transfer is omitted in all previous studies. However, it should be noted that the radiation heat transfer must always be included for the cases of the natural convection environments in all applications. To enhance the radiation heat transfer, the surface of the heat sink is coated with the paint whose emissivity is 0.9 .

In addition, all previous investigations, including References $(5,6)$ are based on the heat sink base at a constant and uniform temperature or heat flux which are never existed in the real systems. The light weight plan fin heat sink has never been used in the large size heat sink such as the current one, especially for outdoor electronics.

To improve the thermal spreading along $6 \mathrm{~mm}$ thick base plate which hosts all three components, the heat pipes are embedded on the base plate. With the embedded heat pipes, the equivalent planar thermal conductivities (Kxy) are estimated to be $1000 \mathrm{~W} / \mathrm{m}-{ }^{\circ} \mathrm{C}$ while the conductivity over the thickness (Kz) is assumed to be $180 \mathrm{~W} / \mathrm{m}-{ }^{\circ} \mathrm{C}$.

It should be noted that previous analyses $(5,6)$ assumed the heat sink base at constant temperature of $80^{\circ} \mathrm{C}$ while the current study assumes various heat loads at discrete locations of the housing base plate. In addition, the ambient temperature is assumed to be $50{ }^{\circ} \mathrm{C}$ at the sea level.

\section{Results and discussion}

For convenience, Flotherm software was used for the detailed CFD analysis. Though the equipment is preferred at the vertical position thermally, however, the system must be able to deplore at any orientation due to the limited surrounding space available. Therefore, two special cases with equipment at the vertical and horizontal position are examined. The temperature profiles for the vertical and horizontal heat sinks are presented in Figures 6 and 7, respectively while the velocity profiles for the vertical and horizontal heat sinks are given in Figures 8 and 9, respectively

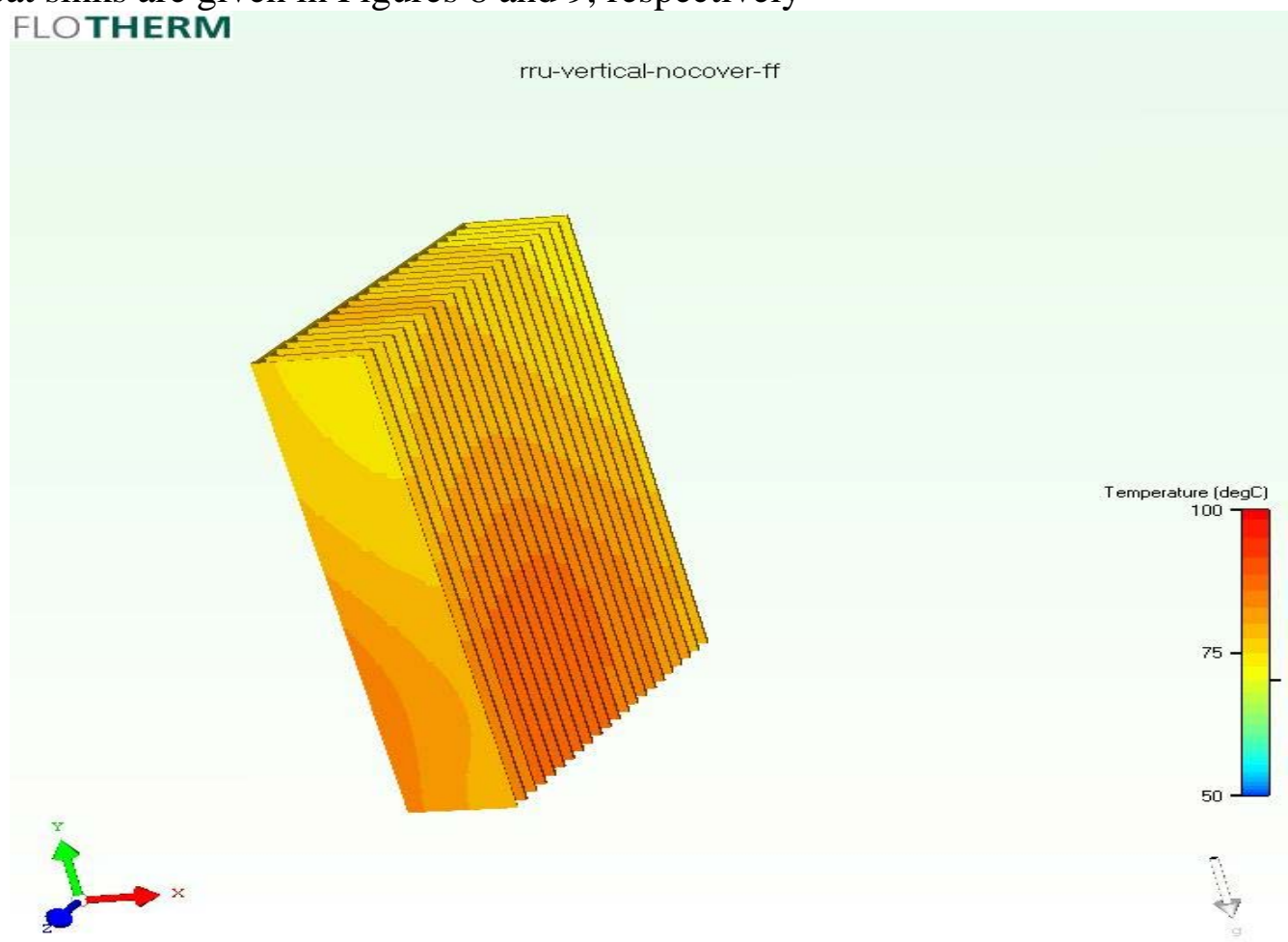

Figure 6 Temperature Profile for Vertical Heat Sink 
rru-horizontal-nocover-ff
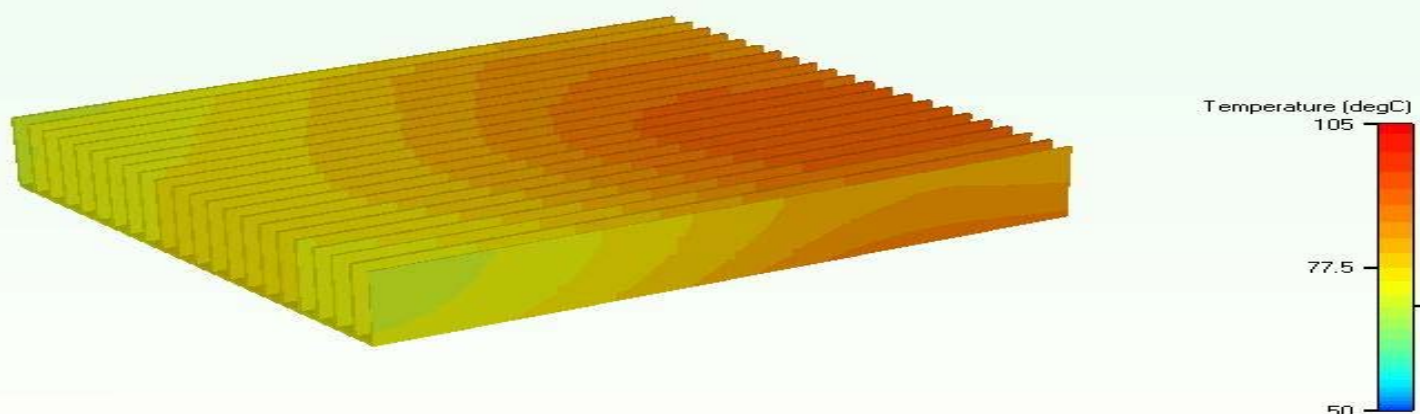

Figure 7 Temperature Profile for Horizontal Heat Sink

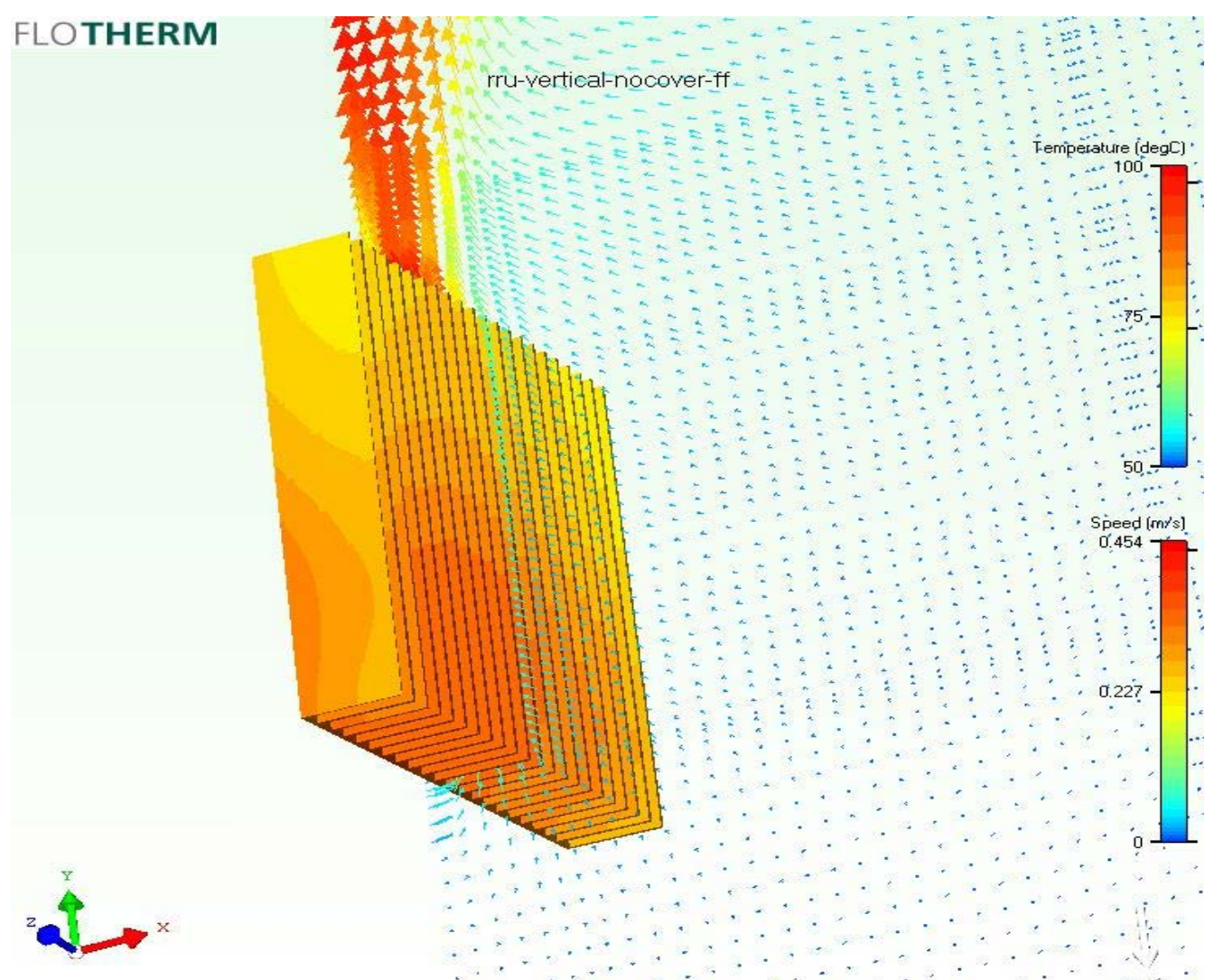

Figure 8 Velocity Profile for Vertical Heat Sink 


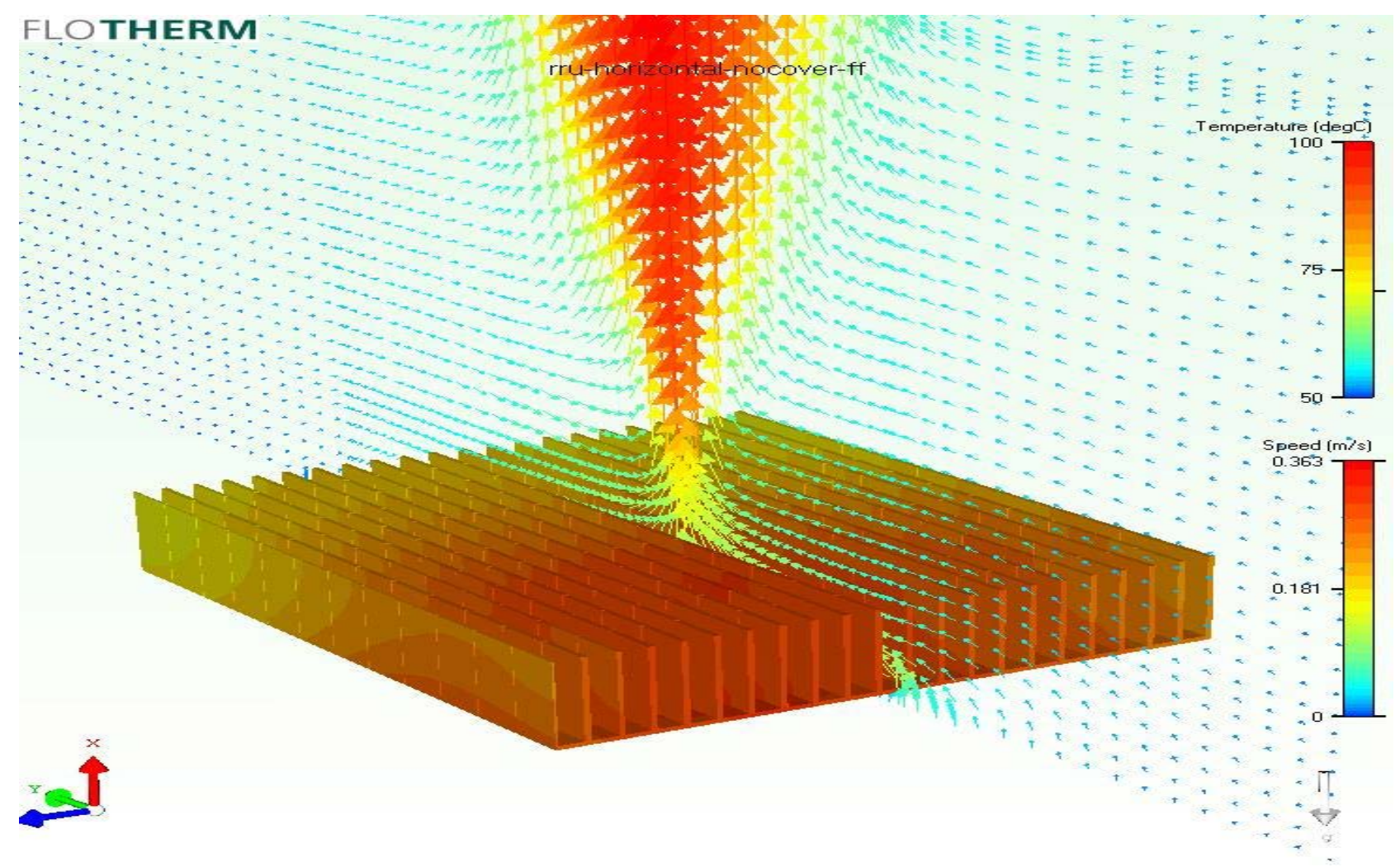

Figure 9 Velocity Profile for Horizontal Heat Sink

The air flow patterns for the vertical and horizontal heat sinks are totally different. For a vertical heat sink, the flow enters not only from the bottom but also from the front face (spaces between fins) of the heat sink. The latter is referred to as the entrained flow. On the other hand, the air flow enters the horizontal heat sink from both ends and follows the fins. The hot air finally exits near the middle of the heat sink and flows upwards.

For structure integrity, the heat sink vendor suggests to add several metal strips over all thin fins across the width of the heat sink. The previous study (6) indicates that a cover to the heat sink will improve the thermal performance for a vertical heat sink. Therefore, the large piece of the cover is chosen instead of several narrow strips. However, it will not work for a horizontal heat sink according to the flow pattern presented in Figure 9 because the hot air would be trapped under the cover. Therefore, two aluminum covers are attached to the heat sink with the central section of the heat sink open for venting the hot air. Both small cover (3” x 10.341” x 0.1”) and large cover (4” x 10.341” x 0.1”0) are one inch from each end. Another reason to utilize the large piece of the cover is for the safety. This is because the fin is so thin and becomes a sharp blade which may injury the person in handling the heat sink. The temperature and velocity profiles are given in Figures 10 and 11 and Figures 12 and 13, respectively for the vertical and horizontal heat sinks. 


\section{FLOTHERM}

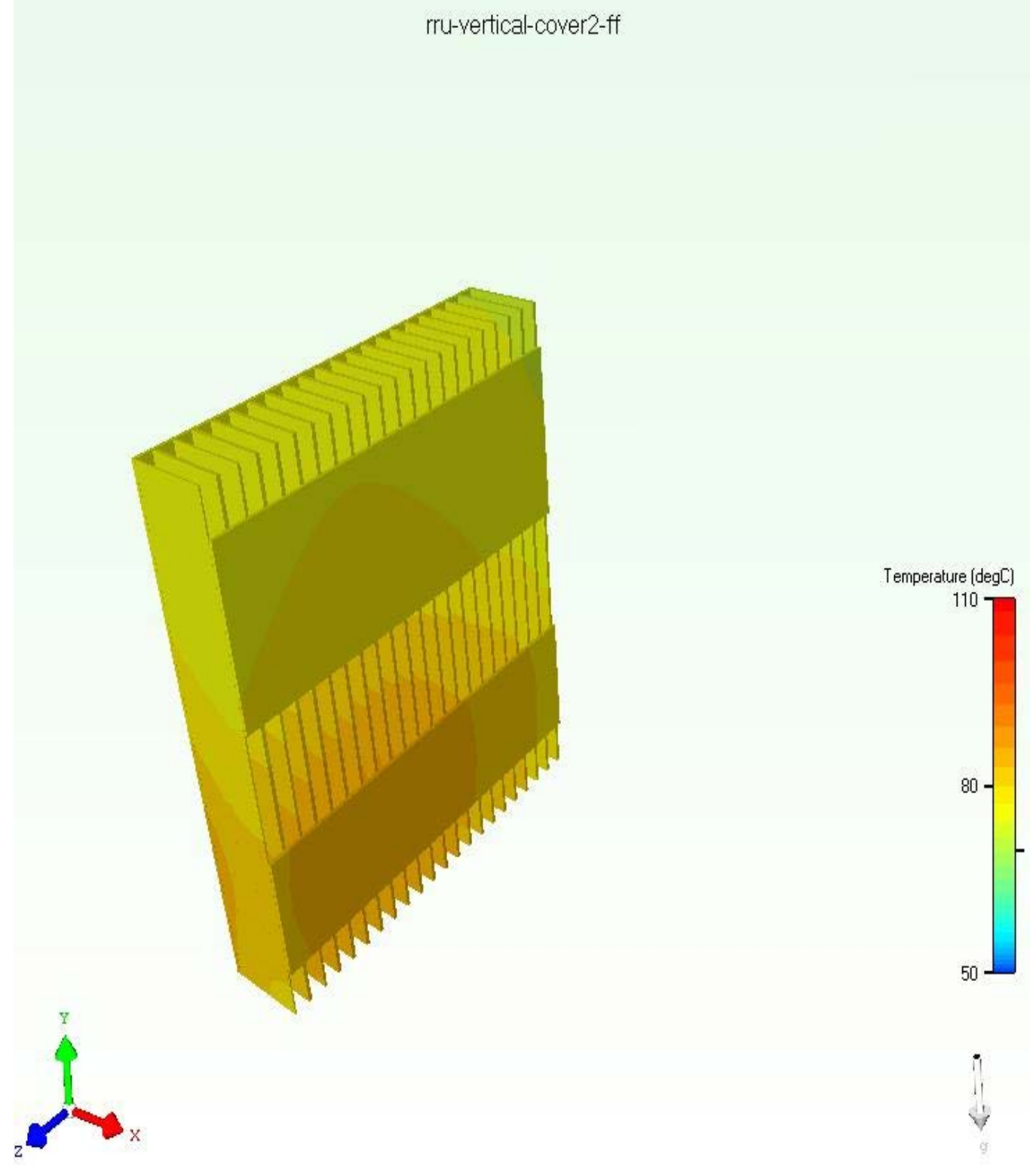

Figure 10 Temperature Profile: Vertical Heat Sink with Covers 


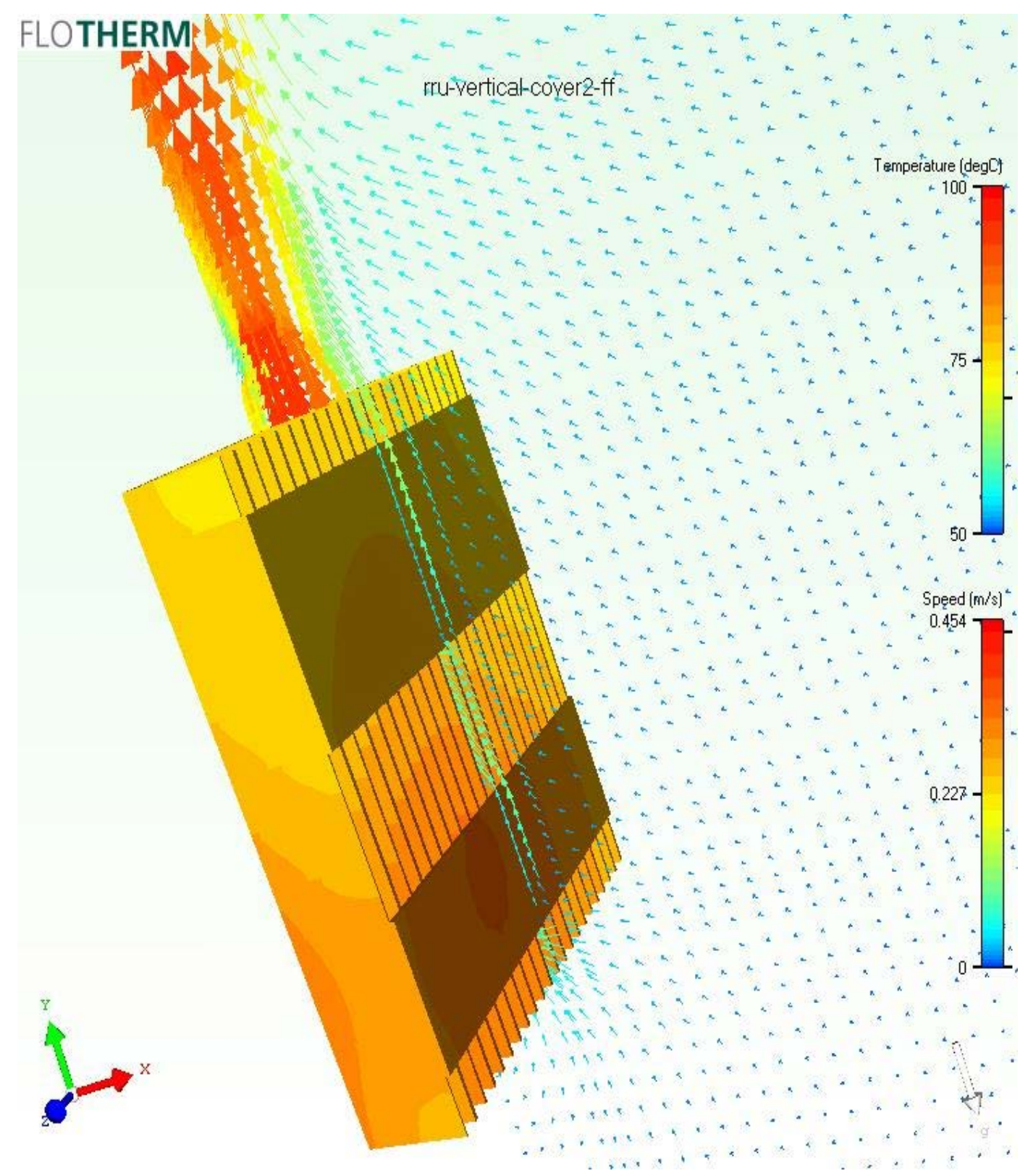

Figure 11 Velocity Profile: Vertical Heat Sink with Covers 


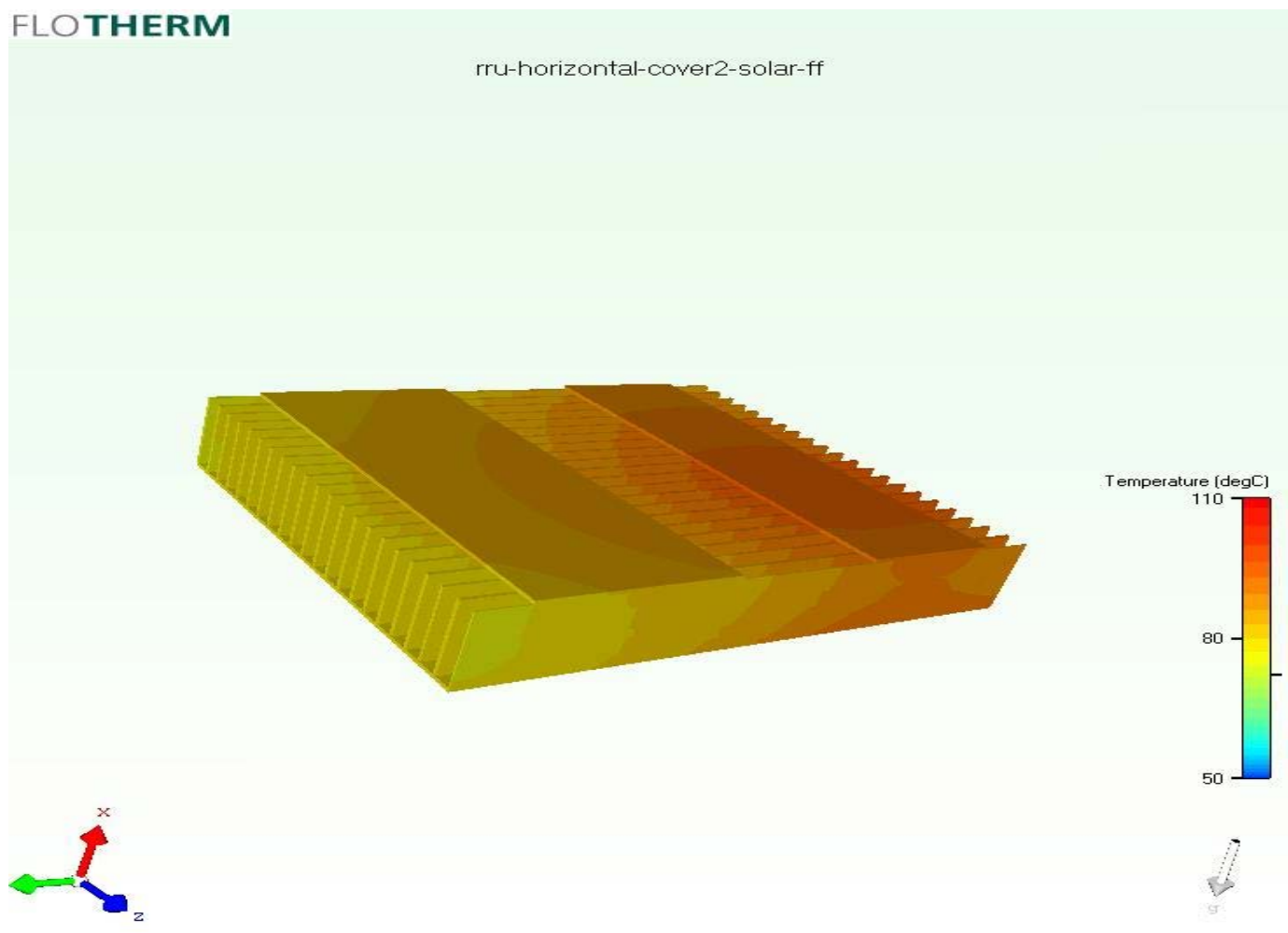

Figure 12 Temperature Profile: Horizontal Heat Sink with Covers

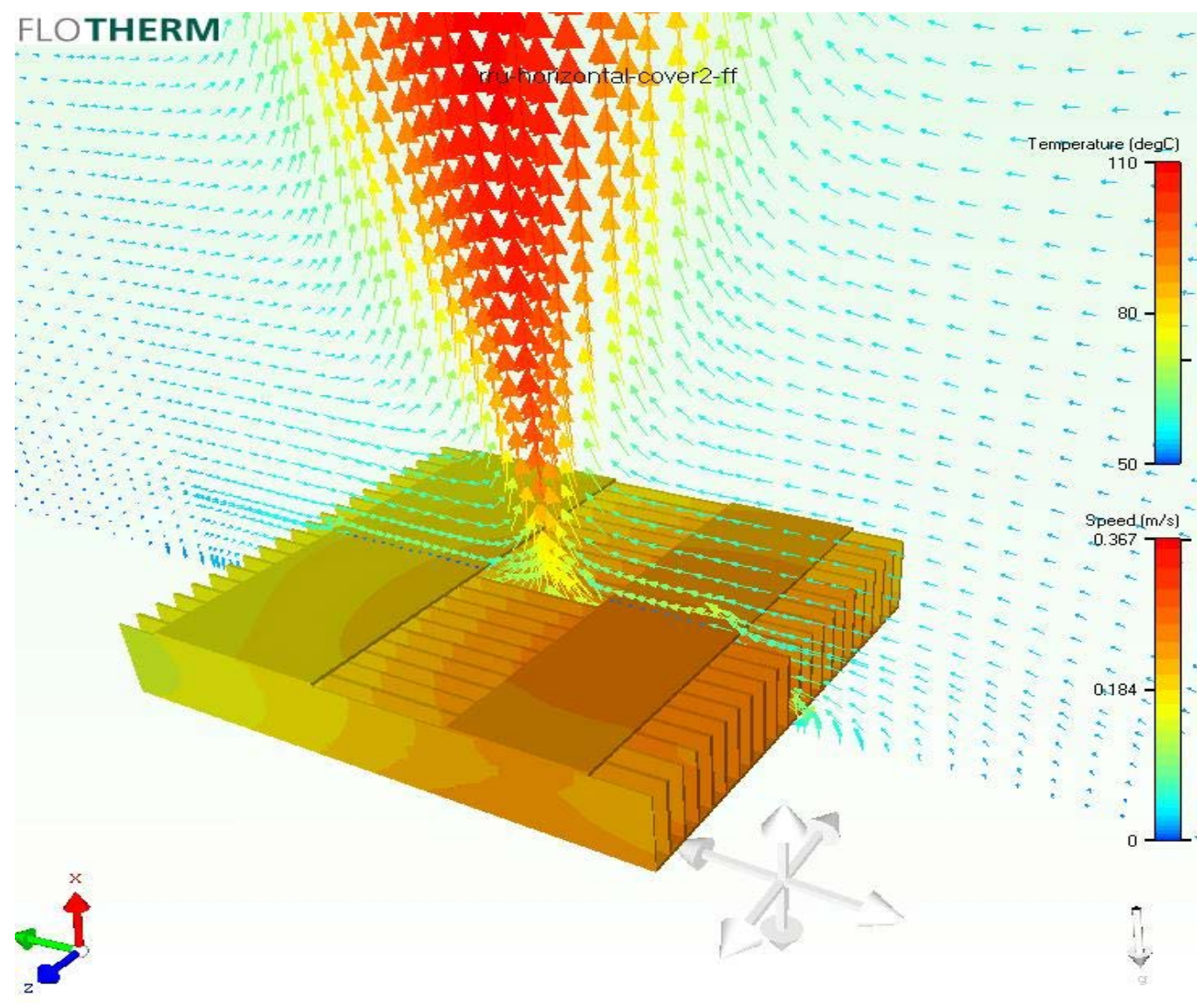

Figure 13 Velocity Profile: Horizontal Heat Sink with Covers 
The summary results for components the covers are presented in Figure 14 for the heat sink at both vertical (V) and horizontal (H) positions without cover and vertical (VC) and horizontal (HC) positions with the cover. As can be seen from the figure, the heat sink cover can improve the component and base plate temperatures for the case with the vertical heat sink. One the other hand, the cover does not have any noticeable effect on the horizontal heat sink.

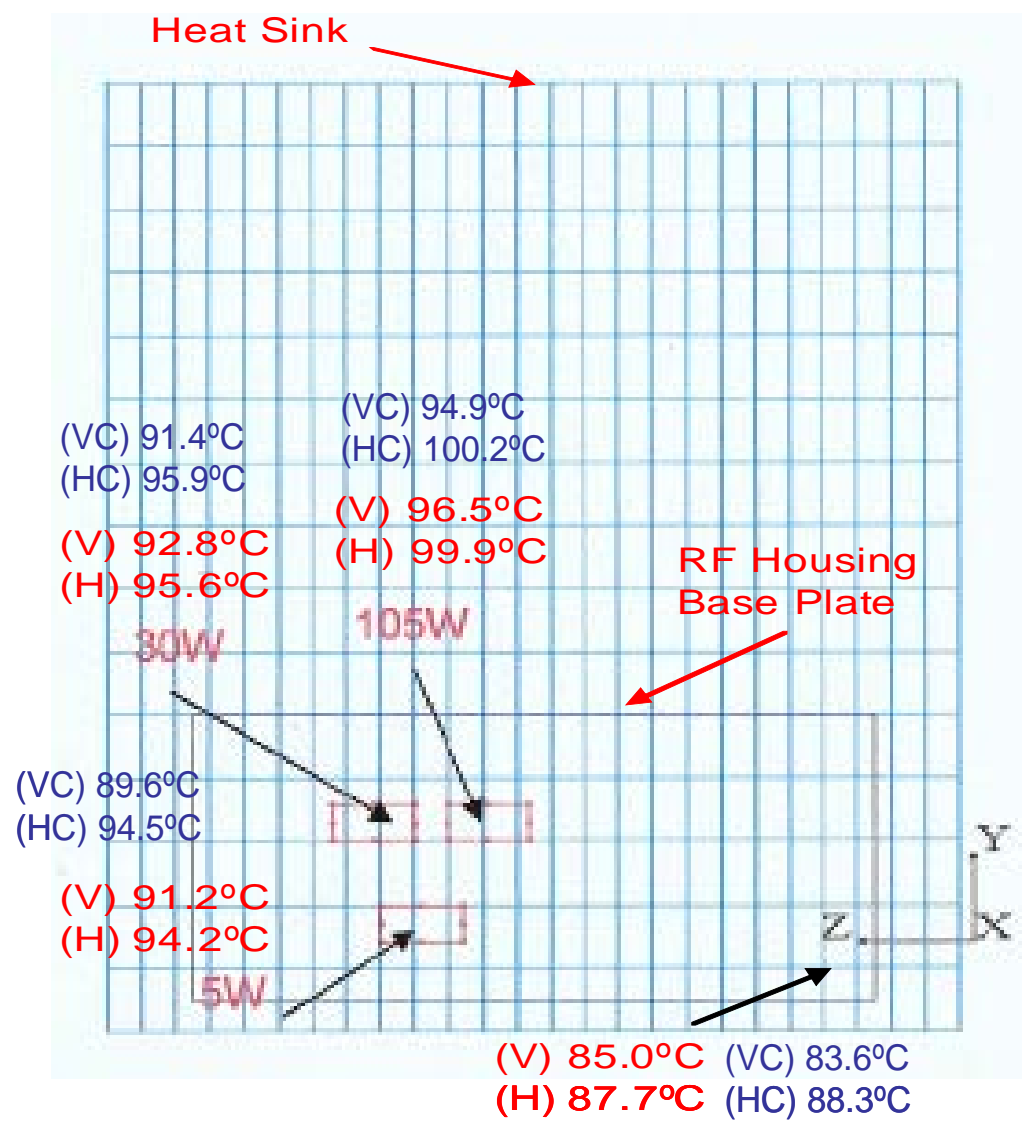

Figure 14 Temperatures of Components and Base Plate

\section{Summary}

The purpose of this work is to employ the knowledge gained from previous studies $(5,6)$ to the development of new products for cooling of the outdoor electronics. In addition, the radiation heat transfer that is omitted in all previous studies is included in the present analysis. Furthermore, the discrete heat sources are considered in the present work as opposed to the common assumptions of uniform temperature (or heat flux) at the heat sink base in all previous work.

The results presented in Figure 14 indicate that the maximum temperature of the base plate in all cases has met the thermal limit of $110^{\circ} \mathrm{C}\left(60^{\circ} \mathrm{C}\right.$ above the ambient at $\left.50^{\circ} \mathrm{C}\right)$.

The heat sink with continuous fin configuration is chosen for the design application because of its superior thermal performance. The results indicated that the vertical heat sink has a better thermal performance over that of the horizontal one. The results also validate the conclusion of the previous analysis (6) that the vertical heat sink with the cover performs better thermally. However, there is no noticeable difference between the cases with and without cover for the horizontal heat sink

The system weight is very important for any tower or pole mounted electronics. Therefore, the newly developed light weight plain fin heat sink is adopted for such applications. The total weight of the heat sink alone is $1.021 \mathrm{~kg}$. The ratio of system power to heat sink weight ratios is $137.1 \mathrm{~W} / \mathrm{kg}$. 
It should be noted that the fin space is optimized for the case with the vertical heat sink. In order to take advantage of the superiority thermal performance of a vertical heat sink under natural convection condition, most of the systems, including the heat sink are recommended to be installed at the vertical position. The optimal fin spacing may vary with the heat sink orientations.

\section{References}

[1] Starner, K.E., and McManus, H. N, “An Experimental Investigation of Free Convection Heat Transfer from Rectangular Fin Arrays”, J Heat Transfer 85, 1963.

[2] Welling, J.R. and Wooldridge, C. R., "Free Convection Heat Transfer Coefficients from Rectangular Vertical Fins", J Heat Transfer 87, 1965.

[3] Izume, K, and Nakamura, H, "Heat Transfer by Convection on Heated surface with Parallel Fins”, Jap. Soc. Mech. Eng., 34, 1969.

[4] Van De Pol, D. W., and Tierney, J.K., “Free Convection Nusselt Number for Vertical U-Shaped Channels”, J Heat Transfer, 95, 1973.

[5] Yeh, L.T., Yeh, Joseph and Chung, B.T. F., “Natural Convection from Finned Heat Sinks”, IPack2007-33036, Vancouver, BC, Canada, July 8-12, 2007.

[6] Yeh, L.T., "Natural Convection from Finned Heat Sinks with/without Cover/Shroud”, 19th International Symposium on Transport Phenomena, Reykjavik, Iceland, August 17th - 21st, 2008.

[7] Yeh, L. T., and Chu, R., C, Thermal Management of Microelectronic Equipment, ASME Press, 2002.

[8] Yeh, L. T., and Chu, R., C, Thermal Management of Telecommunications Equipment, ASME Press, 2013. 